\title{
Integrated product development
}

\author{
TAY ENG HOCK
}

National University of Singapore, Department of Mechanical Engineering, 10 Kent Ridge Crescent, Singapore 119260

e-mail: mpetayeh@nus.edu.sg

\begin{abstract}
Manufacturing and design are very closely related. The manufacturing capabilities available impact the scope of design, while design for manufacturing ensures the economic success of the products.

Furthermore, the major goals of firms in the nineties are to significantly reduce product costs and time to market (TTM). To meet these goals, quality product designs that meet customers' needs have to be developed.

Design methods such as Quality Function Deployment and Pugh's concept selection technique have been used to significantly improve engineering design processes. Developed as separate tools, however, they are difficult to integrate and coordinate in the total design process, since the relationship of the two methods is often unclear.

This paper demonstrates, through a case study, that these methods are in fact results of a similar underlying concept. Design problems and solutions are unified by the concept of engineering models. An engineering model is a set of equations that relates the design variables to the performance metrics used to quantify performance of a product. Together with the engineering models, Quality Function Deployment and Pugh's concept selection technique have been used in the design and development of a hematology machine from concept to prototype.
\end{abstract}

Keywords. Integrated product development; quality function deployment; concept selection technique; time to market; product costs; hematology machine.

\section{Introduction}

The relationship between manufacturing and design has been well recognized. A study done by Westinghouse (1984) shows that $80 \%$ of all life-cycle costs are fixed during the design phase. Good manufacturing techniques cannot compensate for poor design.

Further, in this highly competitive age, for a company the ability to identify products that the customers need is crucial. The degree to which a product satisfies customer desires is a critical product success factor (Hise et al 1990). A consensus is rapidly developing 
in industrial practice that customer desires can only be obtained through actual contact with the customer and that designers are often wrong when they try to guess what the customer wants (Rabino \& Muskowitz 1984). To facilitate customer focus, several structured methodologies and representations for organizing and presenting customer information have been developed. One such representation is the House of Quality (HOQ), which helps product designers to explicitly identify customer requirements, relate them to objective engineering characteristics, identify tradeoffs, and to evaluate the characteristics of a potential product relative to competing products (Hauser \& Clausing 1988). The HOQ provides a product development team with a compact description of three important items

(1) Customer needs and their relation to objective engineering characteristics.

(2) Comparisons with competing products based on objective engineering numbers.

(3) A summary of the engineering tradeoffs inherent in the design.

In a typical situation, marketing staff collect the data about customers and competing products and, possibly with some input from engineering, create the HOQ. They decide a set of performance targets which are then communicated to the designers. There are two specific sources of problems in this process,

(1) Targets set based on the information contained in the HOQ alone are often unrealistic. As a result, designers cannot achieve them and this results in time-consuming iterations until an achievable specification is reached.

(2) The way coupling between design variables is described in the HOQ does not adequately reflect the trade-off that must be made in real design problems.

After understanding the voice of the customers, concepts are generated using brainstorming and these concepts are selected using the method proposed by Pugh (1991). This will be described in a later section using a case study.

In addition to House of Quality and Pugh's Selection Method, designers often have reliable engineering models that they can use to test the limits of product performance. An engineering model is a set of equations that relates the design variables to the performance metrics used to quantify performance of a product.

The synthesis of the methods mentioned above is shown in figure 1 .

\section{Quality function deployment. The house of quality}

The identification of customer needs remains a key aspect of developing robust and successful products. Without customer needs to guide new product design decisions, the products themselves have relatively low probabilities of success in the market. The three key steps that allow a researcher to construct the voice of the customer are as below (figure 2).

(1) Identify unstructured list of customer needs.

(2) Set development priorities by quantifying the relative importance of the different needs.

(3) Translate the quantified needs into specific engineering goals. 


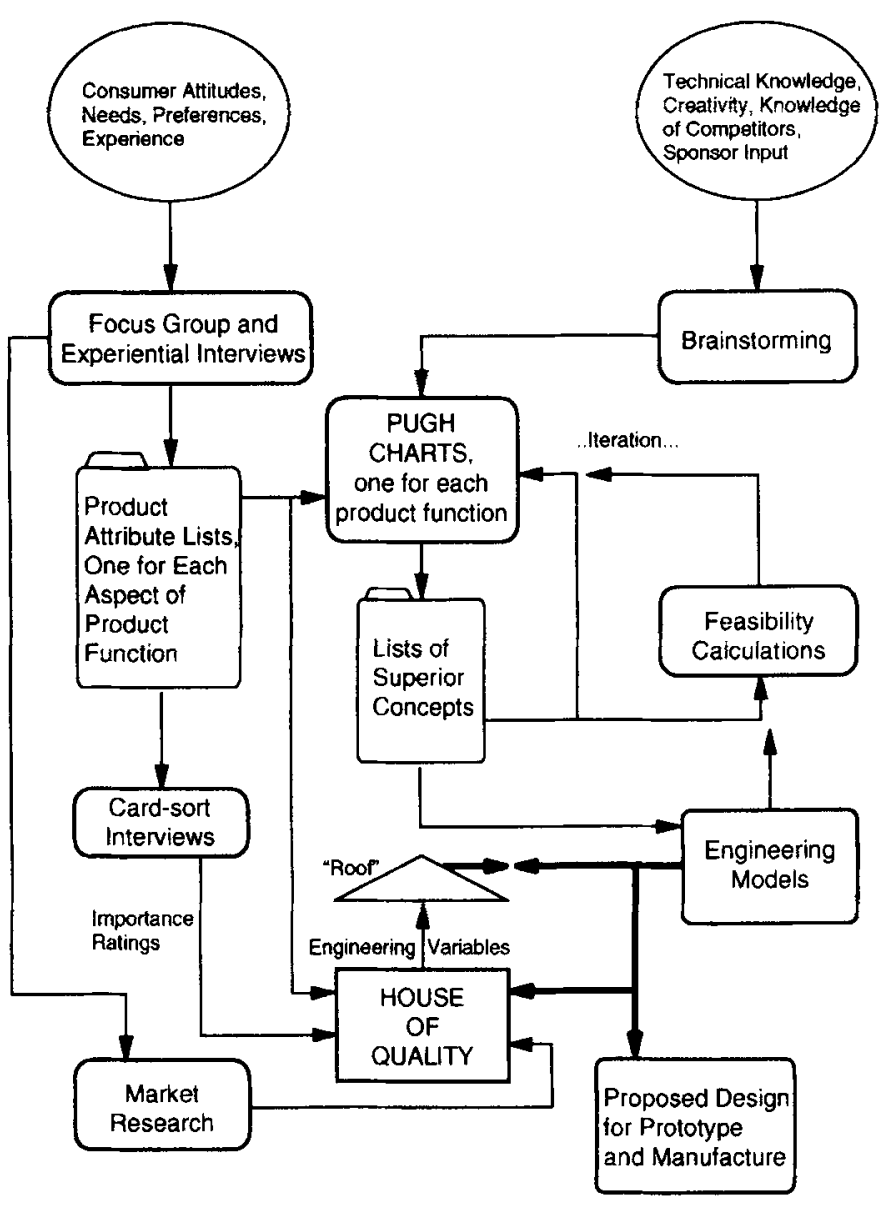

Figure 1. Integrate product design process.

Further, it remains critical that the exact words and vernacular be used throughout the identification, structuring and prioritization process. Without using the exact words of the customer, it may become difficult to identify the nuances of the customer preferences; if the customer voice is constantly processed and re-translated, the final translation may become markedly different from the customer's initial intentions. Because of this need to capture the exact words of the customer, one-on-one interviews and focus groups provide a superior medium other than sales force or distributor reports for producing a rich set of needs.

Further, the interactive one-on-one interviews may provide a more robust set of needs than focus groups because of the opportunity to probe deeper for customer needs, rather than focusing on the obvious issues which a focus group can easily identify.

Hauser and Griffin (Griffin 1989) have also carried out research on identifying how many customers need to be interviewed in order to identify a percentage of the unmet needs. They have created a Beta-binomial model which predicts the percentage of the needs identified given the number of customers interviewed. Based on the model predictions, interviews with sixteen customers identify $80 \%$ of the needs, while thirty interviews would be required to identify $90 \%$ of the needs. Considering the high cost of market research, significant cost savings can be realized by reducing the number of surveyed or interviewed customers. 


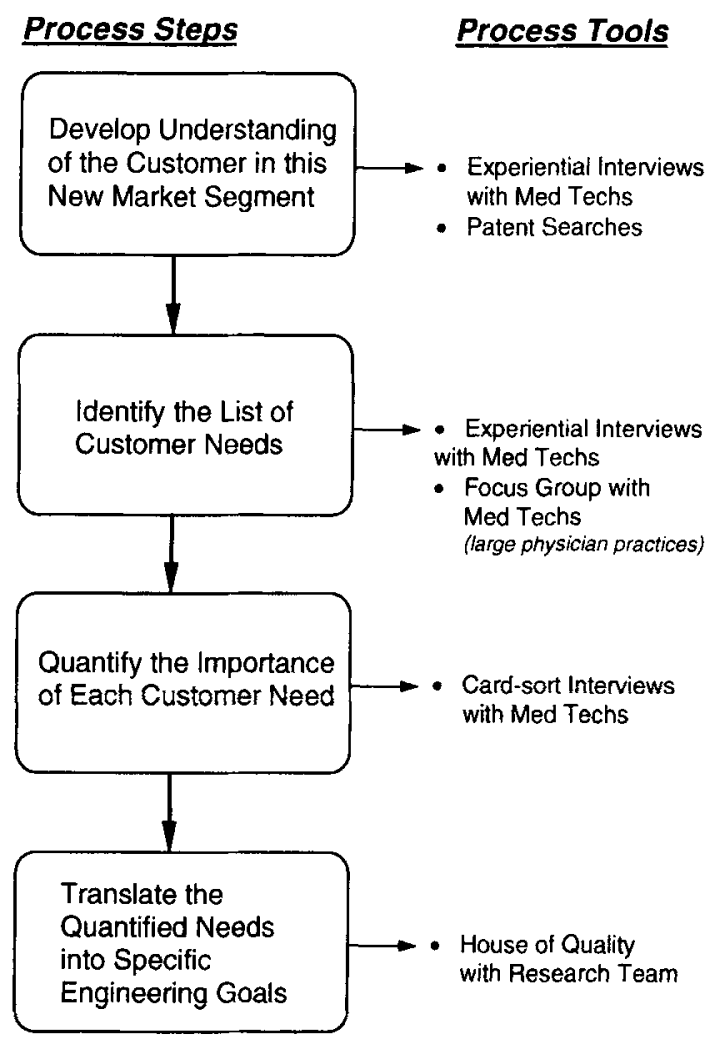

Figure 2. Market research process identifying and applying the voice of the customer.

Hauser and Griffin's model was used to determine the number of customers that we should interview. Through experiential interviews, card-sort interviews, and the focus group, the research team has directly contacted 33 medical technicians who were involved in hematology testing. Based on Hauser and Griffin's model, we should have identified over $90 \%$ of customer needs. Some of the results are shown in tables 1-3. Due to proprietary considerations, not too many details are given on this project in this paper. However, the nature of the project is to design a next generation of hematology equipment for a major corporation in the United States of America.

Table 1. Ten most important needs for physician-practice and medical technicians.

\begin{tabular}{ll}
\hline Importance & \multicolumn{1}{c}{ Customer need } \\
\hline 1 & Achieves level of accuracy equivalent to competitor's machine \\
2 & Accurate even if the blood clots \\
3 & No opening of sample tubes \\
4 & Machine that can be stopped for RUSH job or emergency job ('STAT'). \\
5 & Low sample volumes for automatic testing \\
6 & Analysis time less than a minute \\
7 & Eliminate opening tubes to solve aerosol problem \\
8 & Performs repeat test automatically \\
9 & Not spending a lot of time getting machine started up \\
10 & Reads data and determines whether automatic repeat of abnormal results is necessary \\
\hline
\end{tabular}


Table 2. Examples of translations from customer needs to engineering design requirements.

\begin{tabular}{|c|c|}
\hline Customer needs & Engineering design requirements \\
\hline Machine covers that are easy to remove & $\begin{array}{l}\text { - Time to remove cover } \\
\text { - Number of steps to take apart for repair } \\
\text { - Height, width and depth of the machine }\end{array}$ \\
\hline Eliminate error in patient identification & $\begin{array}{l}\text { - Number of human failure points } \\
\text { - } \\
\text { - Level of redundancy } \\
\text { - } \\
\text { - } \\
\text { Pabeling time } \\
\text { Read and process time for patient identification }\end{array}$ \\
\hline Store quality control information & $\begin{array}{l}\text { - Data storage capacity } \\
\text { - Number of computing resources and functions used } \\
\text { - Number of external access routes }\end{array}$ \\
\hline Eliminate weekly or long-term maintenance & $\begin{array}{l}\text { - Weekly cleaning time } \\
\text { - Mean time for preventive maintenance } \\
\text { - Downtime for preventive maintenance }\end{array}$ \\
\hline 24-Hour service available & $\begin{array}{l}\text { - Repair time } \\
\text { - } 24 \text { Hour maintenance contract availability } \\
\text { - Lead time fotween failure } \\
\text { repair }\end{array}$ \\
\hline Analyse blood in less than a minute & $\begin{array}{l}\text { - Centrifuge spin time } \\
\text { - Scanning time } \\
\text { - } \text { Analysis time } \\
\text { - } \text { Material handling time } \\
\text { - } \text { (read and process time for patient identification }\end{array}$ \\
\hline
\end{tabular}

This QFD process is most effective when collective experiences of a multifunctional team are greater than the sum of the individual experiences. Therefore, the decisions made jointly by the team will consider all the important issues of customer needs, robust technology, manufacturability, and external design.

The relationship matrix in the House of Quality (Hauser \& Clausing 1988) helps the team members to clarify the relationships between requirements and output and serves as a reference document as the design process evolves. The roof of the HOQ provides information on the relationships among the engineering characteristics. Additional columns and rows on the HOQ provide summary information on the technical difficulty of improving engineering characteristics, and the relative position of competitors.

\section{Pugh's concept selection technique}

The Pugh's concept selection technique provides a systematic process for choosing the "best" design out of several, based on attributes that are previously determined. The Pugh process guards against potential weaknesses that might be due to lack of thoroughness in conceptual selection. The process forces the team to consider all types of possible concepts, explain the potential solutions in sketch form, and place the solutions along the horizontal axis of the selection matrix; the team then identifies relevant criteria for 
Table 3. Most important design requirements in physician practices and hospitals ( 10 for most important and 1 for least important).

\begin{tabular}{lcc}
\hline Engineering design requirements & Physicians & Hospitals \\
\hline Increase variability of batch sizes & 4 & 4 \\
Reduce number of steps before walkaway & 6 & 6 \\
Reduce number of steps on return & 4 & 4 \\
Reduce required time between loading & 4 & 4 \\
Include password for supervisor & 5 & 6 \\
Include alternate technology & 5 & 6 \\
Reduce time for maintenance & 5 & 5 \\
Increase automatic maintenance level & 4 & 4 \\
Reduce number of human failure points & 6 & 7 \\
Reduce material handling time & 4 & 4 \\
Reduce downtime for preventive maintenance & 4 & 4 \\
Reduce number of blood exposures & 5 & 4 \\
Reduce number of aerosols & 5 & 4 \\
Reduce number of times disposables handled & 4 & 4 \\
Reduce number of sharps handled & 4 & 6 \\
Increase data storage capacity & 5 & 6 \\
Reduce number of computing resources and functions used & 5 &
\end{tabular}

the concept selection which could come from either customer input or expectations of the design team.

A datum concept is then selected with which all other concepts will be compared against (often, the datum concept is the currently existing design). After establishing the datum, for each individual criteria the other concepts are rated as better $(+)$, worse $(-)$ or the same (S) as the datum. After completing the matrix, it is possible to graphically view which concepts best satisfy a wide range of criteria. Based on the matrix, it is possible that a dominant concept may emerge; it is also possible that some concepts will have a number of relative strengths and weaknesses. Hybridization of the concepts can be placed alongside the initial concepts and "re-pughed" with the same criteria. Thus, this process provides a systematic method of acquiring:

(1) greater insight into specification requirements;

(2) greater understanding of the problem;

(3) greater understanding of potential solutions;

(4) knowledge of why one concept may be stronger than another;

(5) team consensus on all of the above;

(6) a natural stimulus to produce additional concepts.

Moreover, in addition to improving communication across different members in a project team, QFD provides a format for documenting decisions that can be used to guide future decisions. All of the documents produced by the QFD process can be used as documentation for design decisions and product modifications. As a design project progresses, there is often confusion, and second-guessing as to why a previous decision was made. The HOQ and Pugh selection matrices can immediately provide information on the rationale for the previous decisions. Figure 3 shows the results of one of the Pugh matrices for patient identification. 


\begin{tabular}{|c|c|c|c|c|c|c|c|}
\hline $\begin{array}{c}\text { Patient Identification } \\
\text { Concept Selection } \\
\text { Criteria }\end{array}$ & $\begin{array}{l}\text { "Shipping } \\
\text { Tag" }\end{array}$ & $\begin{array}{c}\text { "Bracelet } \\
\& \\
\text { Tube" }\end{array}$ & $\begin{array}{l}\text { "Form } \\
\text { \& Tube } \\
\text { Sticker" }\end{array}$ & $\begin{array}{l}\text { "Form } \\
\& \\
\text { Tube" }\end{array}$ & "Existing" & "Auto" & $\begin{array}{l}\text { "Coded } \\
\text { Tuhe \& } \\
\text { Form" }\end{array}$ \\
\hline System Cost (-) & + & $\mathbf{S}$ & & + & + & - & + \\
\hline $\begin{array}{l}\text { Manual human } \\
\text { interaction with tube } \\
\text { and/or form (-) }\end{array}$ & - & + & & $\mathbf{S}$ & - & + & $\mathbf{S}$ \\
\hline $\begin{array}{l}\text { Number of potential } \\
\text { failure points from } \\
\text { human interaction (-) }\end{array}$ & $\mathbf{S}$ & + & D & $\mathbf{S}$ & - & + & $\mathbf{S}$ \\
\hline $\begin{array}{l}\text { Cost per sample - } \\
\text { disposable cost (-) }\end{array}$ & + & + & $\mathbf{A}$ & $\mathbf{S}$ & + & + & $\mathbf{S}$ \\
\hline $\begin{array}{c}\text { Machine can read } \\
\text { patient identification } \\
(+)\end{array}$ & - & $\mathbf{S}$ & $\mathbf{T}$ & - & - & $\mathbf{S}$ & $\mathbf{S}$ \\
\hline $\begin{array}{c}\text { Ease of buman reading } \\
\text { on tube }(+)\end{array}$ & + & $\mathbf{S}$ & $\mathbf{U}$ & $\mathbf{S}$ & - & + & $\mathbf{S}$ \\
\hline $\begin{array}{l}\text { Reliability in reading } \\
\text { patient identification } \\
\qquad(+)\end{array}$ & $\mathbf{S}$ & $\mathbf{S}$ & $\mathbf{m}$ & $\mathbf{S}$ & - & + & $\mathbf{S}$ \\
\hline $\begin{array}{c}\text { Polential patient } \\
\text { interference with } \\
\text { blood band and } \\
\text { measurement } \\
\text { operation (-) }\end{array}$ & - & + & & + & + & + & $\mathbf{S}$ \\
\hline $\begin{array}{c}\text { Laboratory } \\
\text { information system } \\
\text { (LIS) dependency } \\
(-)\end{array}$ & + & $\mathbf{S}$ & & + & + & + & + \\
\hline SUM & 0 & +4 & $\mathbf{0}$ & +2 & -2 & +6 & +3 \\
\hline
\end{tabular}

Figure 3. Patient identification Pugh chart.

\section{Engineering models}

Many firms designing products, ranging from bearings to automobiles, have developed engineering models for their products. An engineering model is a set of equations that relates the design variables to the performance metrics used to quantify the performance of a product.

These models are used to decide whether designs are feasible, to explore the performance envelope of a design without actually building a physical prototype, and to study the tradeoffs involved in the design. A reliable engineering model is often a key part of the competitive advantage in product design. This is because it allows the designer to experiment with large numbers of possibilities without increasing the design time. Having a model also makes it possible to optimize the performance. Design iterations can be 


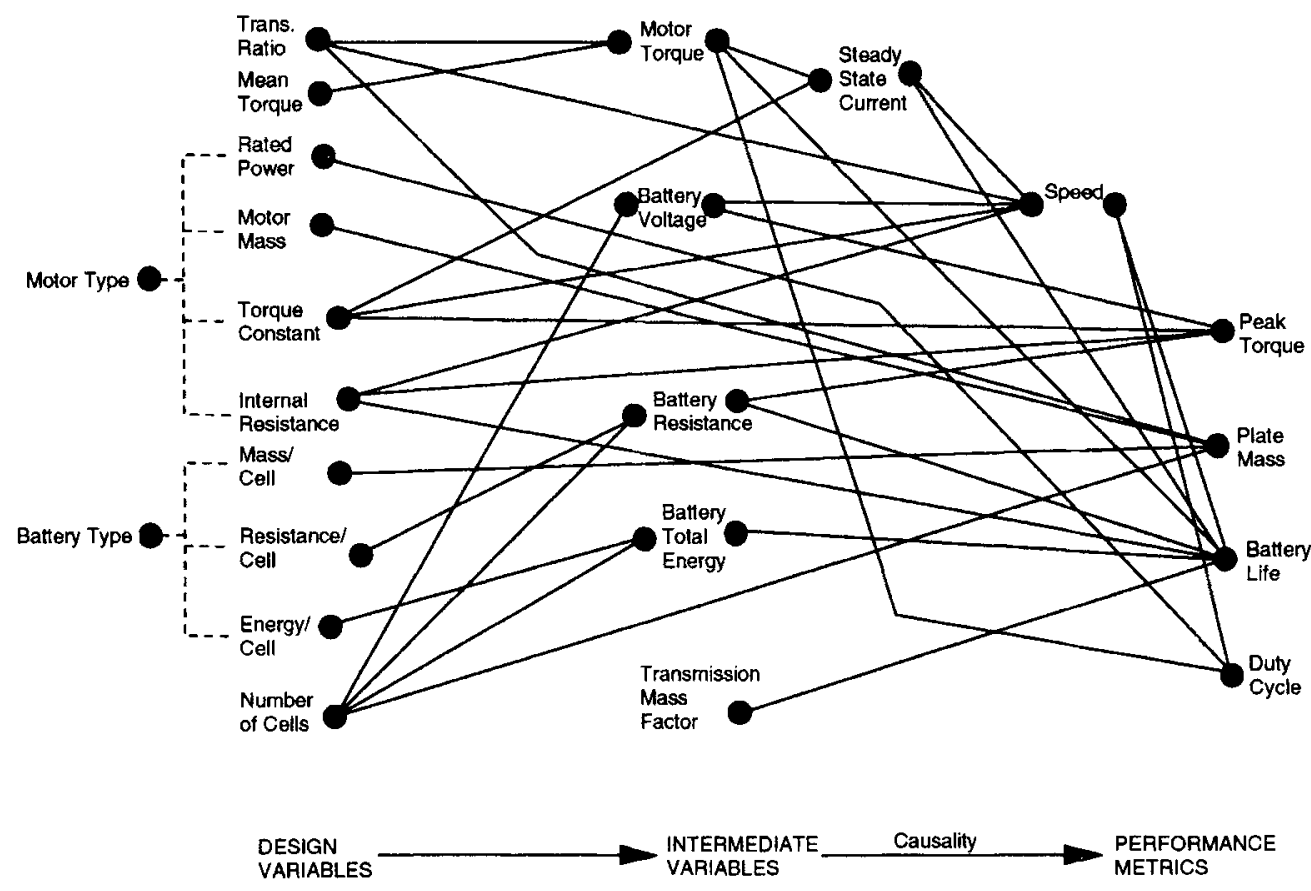

Figure 4. Structure of engineering model for precision centrifuge.

completed rapidly and reliably on the computer without the delays and effort required to build and test prototype hardware.

Figure 4 shows the structure of the engineering model for the precision centrifuge that is required in the design of the hematology equipment.

The inputs to the model are:

(1) Motor torque constant $\left(K_{T}\right)$, internal resistance $\left(R_{M}\right)$ and mass $\left(M_{\text {mot }}\right)$, rated load $\left(P_{R}\right)$. All these get fixed when a particular motor type is chosen;

(2) Battery resistance/cell $\left(R_{\text {cell }}\right)$, battery energy/cell $\left(E_{\text {cell }}\right)$ and mass/cell $\left(M_{\text {cell }}\right)$. All get fixed when a particular battery type is chosen;

(3) Number of cells in the battery $\left(N_{C}\right)$;

(4) Transmission ratio $\left(N_{T}\right)$;

(5) Mean torque ( $\left.\tau_{M}\right)$ at which the tool will be operating.

The outputs of the model are:

(1) Weight of the plate $(M)$;

(2) Speed at rated torque $\left(\omega_{R}\right)$;

(3) Battery life at mean torque $\left(L_{\mathrm{av}}\right)$;

(4) Peak torque $\left(\tau_{\max }\right)$;

(5) Duty cycle $(D)$. 
The engineering model for the precision centrifuge is therefore:

$$
\begin{aligned}
\tau & =\tau_{M} / N_{T}, \\
V & =N_{C} \times 1.2, \\
E & =N_{C} \times E_{\text {cell }}, \\
R_{B} & =N_{C} \times R_{\text {cell }}, \\
I_{A} & =\tau / K_{T}, \\
\omega_{R} & =N_{T}\left(V-I_{A}\left(R_{M}+R_{B}\right)\right) / K_{T}, \\
\tau_{\max } & =V K_{T} /\left(R_{M}+R_{B}\right), \\
L_{\mathrm{av}} & =E /\left(I_{A}^{2} R_{B}+\tau \omega_{R}\right), \\
M & =M_{\mathrm{mot}}+N_{C} M_{\text {cell }}+M_{t} N_{T}, \\
D & =P_{R} /\left(W_{R} \tau\right),
\end{aligned}
$$

where

$\tau: \quad$ motor torque,

$V:$ battery voltage,

$E$ : battery total energy,

$I_{A}:$ steady state current,

$P$ : $\quad$ motor power output,

$M_{t}$ : transmissive mass factor.

Some experimentation with the model makes it clear that many trade-offs are possible in the design. For example:

- energy can be added by using more cells in the battery, but this makes the centrifuge heavier;

- a more efficient motor can be chosen but efficient motors tend to run at higher speeds and so a greater transmission ratio is needed to get the required torque.

Engineering models are useful in conjunction with the House of Quality because they complete the chain from the entities the designers can actually change, the design variables, to what the designer wants to affect, namely, the customer perception of the product.

\section{Final system configuration}

The final system design has two centrifuges, each of which can be loaded with a carousel at any time. When the centrifuges are expeditiously loaded with carousels batched with 20 tubes, the machine can have a maximum achievable throughput (after the first 5 minutes of centrifuging) of 400 assays per hour.

A black and white LCD screen displays patients' blood analyses, quality control and calibration information. The system has the following features:

- walkaway capability;

- diffraction grating optical reading station;

- automatic patient identification;

- Laboratory Information System interface capability. 


\section{Conclusion}

The product development team's group dynamics is critical to the success of a product (Finger \& Dixon 1989). It is important that the team members interact and communicate effectively and understand each other's discipline. The integrated product development incorporating tools from Quality Function Deployment, Pugh Concept Selection Technique and Engineering Model have been found to be effective in this project which involves people from diverse backgrounds.

The author would like to express his sincere gratitude for the opportunities provided in the New Products Program in the Massachusetts Institute of Technology. In particular, he would like to thank Professor Flowers for his guidance in two projects carried out in the program.

\section{References}

Finger S, Dixon J R 1989 A review of research in mechanical engineering design. Part II: Representations, analysis and design for the life cycle. Res. Eng. Design 1: 121-137

Griffin A 1989 Functionally integrated new product development. $\mathrm{Ph} \mathrm{D}$ dissertation, Sloan School of Management, Massachusetts Institute of Technology, Cambridge, MA

Hauser J R, Clausing D 1988 The House of Quality. Harvard Business Review May-June: 63-73

Hise R T, O'Neal L, Parasuraman A, McNeal J U 1990 Marketing/R\&D interaction in new product development: Implications for new product success rates. J. Prod. Innovation Manage. 7: 142155

Pugh S 1991 Total design: Integrated methods for successful product design (Addison-Wesley: New York)

Rabino S, Moskowitz H 1984 Detecting buyer preference to guide product development. J. Prod. Innovation Manage. 1: 140-150

Sriram D, Logcher R, Fukuda S 1989 An object-oriented framework for collaborative engineering design. In Computer-aided cooperative product development (MIT, Cambridge, MA: SpringerVerlag)

Westinghouse 1984 Report on Life Cycle Costs, Westinghouse Productivity and Quality Center, Pittsburgh, PA 